\title{
Penerapan Probabilistic Neural Network pada Klasifikasi Berat Bayi Baru Lahir
}

\section{Prily Dwi Inas Azizah*}

Prodi Statistika, Fakultas Matematika dan Ilmu Pengetahuan Alam, Universitas Islam Bandung, Indonesia.

*prilydwiinasazizah@gmail.com

Abstract. Based on the Government Agency Performance Report of the Banjar City Health Office in 2018, there were 32 cases of Infant Mortality Rate (IMR) with the main causes being Low Birth Weight (LBW) of 56\%, Asphyxia of 30\%, and congenital defects of $14 \%$. Infant mortality due to LBW has a 4 times greater risk compared to babies born weighing more than 2500 grams. If the possibility of giving birth to LBW can be done early, then the incidence of LBW can be minimized. Probabilistic Neural Network (PNN) is an algorithm that uses a probability function. PNN is often used in classification because it can map each input pattern to the optimal number of classifications, is faster, and more accurate than other neural network models. The data used in this study is the medical record data of patients giving birth in 2020 at the Banjar City Regional General Hospital. The response variable in this study was the classification of birth weight, while the predictor variables in this study were maternal age, systolic blood pressure, diastolic blood pressure, maternal weight, maternal height, maternal hemoglobin, parity and gestational duration. The result of this research is the accuracy of $95 \%$ with the proportion of training and testing data distribution is 80:20. The results of the PNN classification on 20 test data, namely there were 17 infants classified into class 1 (normal birth weight) and 3 infants classified into class 2 (low birth weight).

Keywords: Neural Network, Probabilitas Neural Network, and LBW.

Abstrak. Berdasarkan Laporan Kinerja Instansi Pemerintah (LKIP) Dinas Kesehatan Kota Banjar tahun 2018, terdapat sebanyak 32 kasus Angka Kematian Bayi (AKB) dengan penyebab utama yaitu Bayi Berat Lahir Rendah (BBLR) sebesar 56\%, Asfiksia sebesar 30\%, serta cacat bawaan sebesar $14 \%$. Kematian bayi karena BBLR memiliki risiko 4 kali lebih besar dibandingkan dengan bayi lahir dengan berat lebih dari 2500 gram. Apabila kemungkinan ibu melahirkan BBLR dapat dilakukan lebih awal, maka kejadian BBLR dapat diminimalisir. Probabilistic Neural Network (PNN) adalah salah satu algoritma yang menggunakan fungsi peluang. PNN sering digunakan dalam klasifikasi karena dapat memetakan setiap pola input ke jumlah klasifikasi yang optimal, lebih cepat, dan lebih akurat dibandingkan model jaringan saraf lainnya. Data yang digunakan dalam penelitian ini yaitu data rekam medis pasien ibu melahirkan pada tahun 2020 di Rumah Sakit Umum Daerah Kota Banjar. Variabel respon pada penelitian ini yaitu klasifikasi berat bayi lahir sedangkan variabel prediktor dari penelitian ini yaitu usia ibu, tekanan darah sistol, tekanan darah diastol, berat badan ibu, tinggi badan ibu, hemoglobin ibu, paritas dan lama gestasi. Hasil dari penelitian ini yaitu didapat ketepatan akurasi sebesar 95\% dengan proporsi pembagaian data training dan testing sebesar 80:20. Hasil klasifikasi PNN pada 20 data uji yaitu terdapat sebanyak 17 bayi yang diklasifikasikan ke dalam kelas 1 (berat bayi lahir normal) dan diklasifikasikan ke dalam kelas 2 (berat bayi lahir rendah).

Kata Kunci: Neural Network, Probabilitas Neural Network, dan BBLR. 


\section{A. Pendahuluan}

Suatu negara dapat dikatakan maju apabila negara tersebut memiliki kualitas penduduk yang tinggi. Salah satu penentu kualitas penduduk suatu negara yaitu tingkat kesehatannya. Angka Kematian Bayi (AKB) menjadi salah satu alat ukur dalam menentukan tingkat kesehatan, apabila tingkat $\mathrm{AKB}$ suatu negara tinggi berarti kesehatan lingkungan dan masyarakatnya rendah [1]. Salah satu target Sustainable Development Goals (SDGs) di Indonesia ialah menurunkan AKB menjadi kurang dari 25 per 1000 kelahiran hidup pada tahun 2030. Faktanya, grafik AKB di Indonesia memang mengalami penurunan dari tahun ke tahunnya. Hasil Survei Demografi dan Kesehatan Indonesia tahun 2017 menunjukan bahwa AKB mengalami penurunan yang cukup signifikan, dari 68 kematian per 1000 kelahiran hidup pada 1991 menjadi 24 kematian per 1000 kelahiran hidup pada tahun 2017. Walaupun terus mengalami penurunan, berdasarkan ASEAN Millenium Development Goals tahun 2017, Indonesia masih menjadi negara dengan AKB tertinggi kedua di Asia Tenggara [2].

Jawa Barat merupakan provinsi dengan jumlah penduduk terbanyak di Indonesia, dengan jumlah penduduk sebanyak 48.274.162 jiwa. Berbanding lurus dengan jumlah penduduk yang tinggi, tingkat AKB pun juga tinggi dan menjadikan Provinsi Jawa Barat sebagai salah satu provinsi yang berkontribusi besar terhadap tingginya AKB di Indonesia. Hal tersebut dibuktikan dengan laporan Dinas Kesehatan Jawa Barat [3] yang menyatakan bahwa terjadi peningkatan AKB, dari 3072 kasus pada tahun 2016 menjadi 3077 kasus pada tahun 2017. Di Provinsi Jawa Barat yang mempunyai AKB tertinggi yaitu Kota Banjar dengan persentase sebanyak 13.07 per 1000 kelahiran hidup [3]. Berdasarkan Laporan Kinerja Instansi Pemerintah (LKIP) Dinas Kesehatan Kota Banjar [4], terdapat sebanyak 32 kasus AKB dengan penyebab utama yaitu Bayi Berat Lahir Rendah (BBLR) sebesar 56\%, Asfiksia sebesar 30\%, serta cacat bawaan sebesar 14\%. Kematian bayi karena BBLR memiliki risiko 4 kali lebih besar dibandingkan dengan bayi lahir dengan berat lebih dari 2500 gram [5].

BBLR merupakan bayi yang lahir dengan berat badan kurang dari 2500 gram tanpa memandang masa kehamilan [6]. BBLR dapat dipengaruhi oleh beberapa faktor diantaranya faktor maternal (faktor ibu), faktor janin serta faktor lingkungan [7]. Apabila hal-hal tersebut diketahui lebih awal, maka dapat dilakukan pencegahan dan persiapan yang lebih matang. Hal ini tentunya bisa meminimalisir tingkat BBLR serta menurukan tingkat AKB di Kota Banjar. Untuk bisa dilakukan pencegahan dan persiapan yang lebih matang maka harus diketahui dahulu kemungkinan ibu melahirkan BBLR. Untuk mengetahui kemungkinan tersebut, maka dapat dilakukan klasifikasi terhadap pasien ibu melahirkan berdasarkan faktor-faktor diatas. Pada penelitian ini, klasifikasi tersebut dilakukan dengan menggunakan salah satu model Neural Network, yaitu Probabilistic Neural Network .

Salah satu model NN yang biasa digunakan yaitu Probabilistic Neural Network (PNN). PNN adalah suatu algoritma yang menggunakan fungsi peluang. PNN sering digunakan dalam klasifikasi karena dapat memetakan setiap pola input ke jumlah klasifikasi yang optimal, lebih cepat, dan lebih akurat dibandingkan model jaringan saraf lainnya [8]. Proses klasifikasi dilakukan hanya dalam satu tahap sehingga prosesnya sedikit lebih cepat dibandingkan algoritma Neural Network lainnya. Dalam Probabilistic Neural Network terdapat tiga lapisan yaitu lapisan input, lapisan pola, dan lapisan penjumlahan [9].

Berdasarkan latar belakang masalah yang telah dijelaskan sebelumnya, maka dalam penelitian ini akan dilakukan klasifikasi status BBL berdasarkan faktor maternal pada pasien ibu melahirkan di Rumah Sakit Umum Daerha Kota Banjar periode 2020 dengan menggunakan metode Probabilistic Neural Network.

\section{B. Metodologi Penelitian}

Metode yang digunakan dalam penelitian ini yaitu Probabilistic Neural Network. Data yang digunakan pada penelitian ini yaitu data pasien ibu melahirkan di Rumah Sakit Umum Daerah Kota Banjar pada kurun waktu tahun 2020 dari bulan Januari sampai bulan Desember. Sebanyak 100 rekam medis pasien ibu melahirkan dikumpulkan untuk dianalisis dengan variabel yang diambil sebanyak 11 variabel. Di dalam data tersebut terdapat 64 bayi yang lahir dengan berat 
badan normal dan 36 bayi yang lahir dengan berat badan rendah. Variabel respon pada penelitian ini yaitu klasifikasi berat bayi lahir (Y) yang dibagi menjadi 2 kategori diantaranya, berat bayi lahir dikatakan normal apabila $\geq 2500$ gr dan berat bayi lahir dikatakan BBLR apabila $<2500$ gr. Sedangkan variabel predictor dari penelitian ini yaitu usia ibu $\left(\mathrm{X}_{1}\right)$, tekanan darah sistol $\left(\mathrm{X}_{2}\right)$, tekanan darah diastol $\left(\mathrm{X}_{3}\right)$, berat badan ibu $\left(\mathrm{X}_{4}\right)$, tinggi badan ibu $\left(\mathrm{X}_{5}\right)$, hemoglobin ibu $\left(\mathrm{X}_{6}\right)$, paritas $\left(\mathrm{X}_{7}\right)$ dan lama gestasi $\left(\mathrm{X}_{8}\right)$. Berikut variabel yang digunakan dalam penelitian :

Tabel 1. Variabel Penelitian

\begin{tabular}{|c|c|c|}
\hline Variabel & Keterangan & Satuan \\
\hline $\mathrm{X}_{1}$ & Usia ibu & Tahun \\
\hline $\mathrm{X}_{2}$ & Tekanan darah sistol & $\mathrm{mmHg}$ \\
\hline $\mathrm{X}_{3}$ & Tekanan darah diastol & $\mathrm{mmHg}$ \\
\hline $\mathrm{X}_{4}$ & Berat badan ibu & $\mathrm{kg}$ \\
\hline $\mathrm{X}_{5}$ & Tinggi badan ibu & $\mathrm{g} / \mathrm{dL}$ \\
\hline $\mathrm{X}_{6}$ & Hemoglobin ibu & $\mathrm{Anak}$ \\
\hline $\mathrm{X}_{7}$ & Paritas & $\mathrm{Minggu}$ \\
\hline $\mathrm{X} 8$ & Lama Gestasi & $\mathrm{BBL}<2500 \mathrm{gr}=1$ \\
\hline $\mathrm{Y}$ & Berat bayi lahir & $\mathrm{BBL} \geq 2500 \mathrm{gr}=2$ \\
\hline
\end{tabular}

\section{Probabilistic Neural Network}

Dasar dari PNN adalah teorema Bayesian dan algoritma Kernel Fisher Discriminant Analysis. Teorema Bayesian berguna untuk melakukan klasifikasi pada sebuah data. Sedangkan analisis diskriminan Kernel-Fisher menjadikan operasi ke dalam multilayered feedforward network dengan empat lapisan yaitu input layer, pattern layer, summation layer dan output layer. PNN menggunakan fungsi aktivasi dilapisan kedua yaitu hidden layer yang bertugas untuk membuat decision function. Fungsi tersebut lalu akan dijumlahkan pada summation layer, hasil dari penjumlahan ini merupakan probabilitas. Sehingga probabilitas yang paling maksimum akan masuk ke dalam sebuah kelas yang spesifik [11]. Struktur jaringan PNN dapat dilihat pada Gambar 1

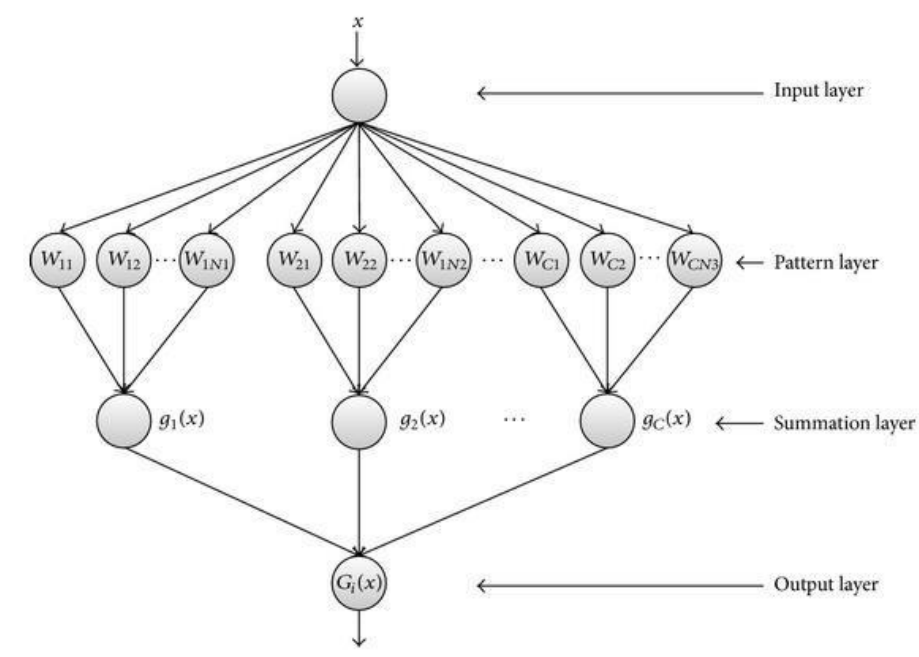

Gambar 1. Struktur Probabilistic Neural Network

1. Input Layer Input Layer merupakan lapisan masukan pada metode PNN .Pada lapisan ini akan dipanggil nilai beberapa parameter yang akan digunakan untuk pelatihan. Setelah melakukan proses pelatihan, maka lapisan input akan memanggil data lain untuk 
melakukan tes pada jaringan yang telah terbentuk dari hasil pelatihan diawal.

2. Pattern Layer

Pada lapisan ini dilakukan perhitungan jarak antara vektor bobot dengan vektor input.

Proses yang terjadi pada lapisan ini menggunakan persamaan. Nilai smoothing parameter ditentukan secara trial and error.

3. Summation Layer

Pada lapisan ini dilakukan penjumlahan kemungkinan maksimum dari setiap unit neuron pada setiap lapisan pattern layer dengan kelas yang sama dan dirata-ratakan dengan jumlah data uji masing-masing kelas.

4. Output Layer

Di lapisan ini akan dibandingkan nilai antara hasil dari keduan kelas. Nilai probabilitas yang tertinggi maka akan dikelompokan menjadi kelas tersebut. Berikut persamaan 2.3 yang digunakan.

Pada algoritma PNN, matriks data training akan dimisalkan dengan matriks data V. Adapun algoritma PNN yaitu sebagai berikut:

1. Menetapkan matriks input $X$, yang terdiri dari dua matriks yaitu $X_{\text {testing }}$ dan matriks $\mathrm{X}_{\text {training. }}$

$$
X=\left[\begin{array}{cccccc}
X_{11} & X_{12} & \cdots & X_{1 j} & \cdots & X_{1 p} \\
X_{21} & X_{22} & \cdots & X_{2 j} & \vdots & X_{2 p} \\
\vdots & \vdots & \vdots & \vdots & \vdots & \vdots \\
X_{k 1} & X_{k 2} & \cdots & X_{k j} & \cdots & X_{k p} \\
\vdots & \vdots & \vdots & \vdots & \vdots & \vdots \\
X_{q 1} & X_{q 2} & \cdots & X_{q j} & \cdots & X_{q p}
\end{array}\right]
$$

Dimana $\mathrm{k}=1,2, \ldots, \mathrm{q}$ dan $\mathrm{j}=1,2, \ldots, \mathrm{p}$

2. Menetapkan matriks target $\mathrm{W}$ yang bersesuaian dengan matriks $\mathrm{V}$.

Dimana $i=1,2, \ldots, \mathrm{n}$

$$
V=\left[\begin{array}{cccccc}
V_{11} & V_{12} & \cdots & V_{1 j} & \cdots & V_{1 p} \\
V_{21} & V_{22} & \cdots & V_{2 j} & \vdots & V_{2 p} \\
\vdots & \vdots & \vdots & \vdots & \vdots & \vdots \\
V_{k 1} & V_{k 2} & \cdots & V_{k j} & \cdots & V_{k p} \\
\vdots & \vdots & \vdots & \vdots & \vdots & \vdots \\
V_{q 1} & V_{q 2} & \cdots & V_{q j} & \cdots & V_{q p}
\end{array}\right] ; W=\left[\begin{array}{c}
W_{1 h} \\
W_{2 h} \\
\vdots \\
W_{i h} \\
\vdots \\
W_{n h}
\end{array}\right]
$$

$$
h=\text { kelas data yang bersesuaian dengan data training }(1,2, \ldots, \mathrm{r})
$$

3. Menentukan nilai $\sigma$ (smoothing parameter) secara trial and error, antara 0 dan 1 .

4. Menentukan bobot bias lapisan input.

$$
b_{i}=\sqrt{\frac{-\ln (0.5)}{\sigma}}
$$

5. Mencari jarak matriks $\mathrm{X}$ terhadap matriks $\mathrm{V}$ dengan persamaan sebagai berikut:

$$
D_{k i}=\sqrt{\sum_{j=1}^{p}\left(X_{k j}-V_{i j}\right)^{2}}
$$

6. Mencari nilai aktivasi $a_{k i}$ dengan persamaan sebagai berikut:

$a_{k i}=e^{-(\text {biDki)2 }} ;$ dengan $i=1,2, \ldots, n$

7. Mencari nilai $c_{k} h$ dengan persamaan sebagai berikut:

$c_{k} h=\sum_{\mathrm{i}=1}^{n}\left(a_{k i} W_{i} h\right) ;$ dengan $h=1,2, \ldots, r$

8. Mencari nilai maksimum (z) hingga $c_{k h}=\max \left\{c_{k h} \mid h=1,2, \ldots, \mathrm{r}\right\}$.

9. Menetapkan $\mathrm{z}$ sebagai kelas dari $\mathrm{X}_{\mathrm{k}}$.

\section{Tahapan Penelitian}

1. Input data berat bayi lahir sebagai variabel respon sedangkan sisanya dimasukkan sebagai variabel prediktor.

2. Melakukan persiapan data diantaranya dengan data cleaning dan data transformation.

3. Membagi data menjadi dua bagian yaitu data training dan data testing dengan menggunakan metode holdout. 
Salah satu metode estimasi kinerja metode klasifikasi yang sederhana adalah metode holdout. Metode holdout membagi data pengamatan menjadi dua bagian yang digunakan secara berurut untuk tahap pelatihan dan pengujian [10].

4. Menjalankan algoritma Probabilistic Neural Network untuk data training dan data testing.

5. Setelah terbentuk suatu pola dari data training, maka dilakukan pengujian pola dengan data testing.

6. Menghitung nilai akurasi dan tingkat kesalahan prediksi dari data training dan testing dengan menggunakan persamaan.

7. Ulangi langkah 1 sampai 6 sehingga diperoleh nilai akurasi yang tinggi.

8. Membuat prediksi klasifikasi risiko BBLR dengan model terbaik.

\section{Hasil Penelitian dan Pembahasan}

\section{Persiapan Data}

Tahapan ini dilakukan untuk mempersiapkan data mentah menjadi data siap pakai untuk dilakukan analisis. Tahapan ini terdiri dari data cleaning dan data transformation. Pada tahapan data cleaning dilakukan proses pembersihan data, bisa dilakukan dengan beberapa cara diantaranya penghapusan beberapa variabel yang tidak sesuai serta penghapusan atau pengisian data yang tidak lengkap. Pada tahapan ini, penulis menghapus 2 variabel yang tidak tepat dan tidak sesuai untuk dijadikan variabel prediktor. Variabel yang dihapus yaitu variabel respirasi dan denyut nadi ibu, sehingga data hanya terdiri dari 8 variabel prediktor dan 1 variabel respon.

Transformasi data dilakukan untuk menghindari data yang rusak dan tidak valid, salah satu cara tranformasi data yaitu dengan normalisasi. Pada tahap ini penulis melakukan normalisasi data menggunakan software SPSS, hasilnya sebagai berikut:

Tabel 2. Hasil Normalisasi Data

\begin{tabular}{|c|c|c|c|c|c|c|c|c|c|}
\hline No. & Usia ibu & $\begin{array}{c}\text { Tekanan } \\
\text { darah } \\
\text { sistol }\end{array}$ & $\begin{array}{c}\text { Tekanan } \\
\text { darah } \\
\text { diastol }\end{array}$ & BB ibu & TB ibu & $\mathrm{Hb}$ ibu & Paritas & $\begin{array}{l}\text { Lama } \\
\text { gestasi }\end{array}$ & BBL \\
\hline 1 & $\begin{array}{c}- \\
0.41414 \\
\end{array}$ & 0.52995 & 1.08464 & -0.287 & $\begin{array}{l}- \\
0.73503 \\
\end{array}$ & 2.24052 & $\begin{array}{c}- \\
0.87534 \\
\end{array}$ & 0.44918 & 1 \\
\hline 2 & $\begin{array}{c}- \\
0.72788 \\
\end{array}$ & $\begin{array}{c}- \\
1.09069\end{array}$ & $\begin{array}{l}- \\
0.88982\end{array}$ & 1.61495 & $\begin{array}{l}- \\
0.00872\end{array}$ & $\begin{array}{c}- \\
0.40576\end{array}$ & $\begin{array}{c}- \\
0.87534\end{array}$ & $\begin{array}{c}- \\
3.53766\end{array}$ & 1 \\
\hline 3 & 0.84082 & 0.93511 & 1.08464 & 0.65446 & $\begin{array}{l} \\
0.88029\end{array}$ & 0.1823 & 1.02757 & 0.98076 & 1 \\
\hline 4 & 0.99769 & 1.34027 & 1.74279 & 1.04436 & $\begin{array}{l} \\
0.58977\end{array}$ & 0.37832 & 0.07612 & $\begin{array}{c}- \\
0.61397 \\
\end{array}$ & 2 \\
\hline 5 & $\begin{array}{c}- \\
0.25727 \\
\end{array}$ & 1.34027 & 1.08464 & 0.56887 & $\begin{array}{l}- \\
0.44451\end{array}$ & -0.7488 & $\begin{array}{c}- \\
0.87534 \\
\end{array}$ & 0.71497 & 1 \\
\hline$\cdots$ & $\ldots$ & $\ldots$ & $\ldots$ & $\ldots$ & $\ldots$ & $\ldots$ & $\ldots$ & $\ldots$ & $\cdots$ \\
\hline 98 & $\begin{array}{c}- \\
0.25727\end{array}$ & 0.12479 & $-\overline{0} 23167$ & $\begin{array}{c}- \\
0.00171\end{array}$ & 1.00813 & $\begin{array}{c}- \\
0.16074 \\
\end{array}$ & 0.07612 & 0.71497 & 2 \\
\hline 99 & 0.68395 & $\begin{array}{c}- \\
0.28037 \\
\end{array}$ & $-\overline{0}-23167$ & 1.32965 & 0.28181 & 2.19151 & 1.02757 & 0.44918 & 1 \\
\hline 100 & $\begin{array}{c}- \\
0.57101 \\
\end{array}$ & $\begin{array}{c}- \\
1.09069 \\
\end{array}$ & $\begin{array}{l}- \\
1.54798\end{array}$ & 0.18848 & 0.13655 & $\begin{array}{c}- \\
0.50377\end{array}$ & $\begin{array}{c}- \\
0.87534\end{array}$ & $\begin{array}{c}- \\
1.14555\end{array}$ & 1 \\
\hline
\end{tabular}

\section{Analisis dan Pemodelan Probabilistic Neural Network}

Pada tahapan ini akan dilakukan klasifikasi terhadap data berat bayi lahir menggunakan algoritma PNN dengan bantuan bahasa pemrograman phyton serta menggunkan tools neupy. Sebelum dilakukan klasifikasi data, dilakukan pembagian data dengan menggunakan metode holdout. Pembagian data dilakukan sebanyak lima kali dengan proposi data training dan data testing yaitu 50:50, 60:40, 70:30, 80:20, dan 90:10. Setelah itu dilakukan perhitungan akurasi 
dan dilihat akurasi terbesarnya, berikut merupakan hasil perhitungan akurasi:

Tabel 3. Nilai Akurasi

\begin{tabular}{|c|c|c|c|}
\hline \multirow{2}{*}{ No. } & \multirow{2}{*}{ Proporsi Pembagian } & \multicolumn{2}{|c|}{ Akurasi } \\
\cline { 3 - 4 } & & Training & Testing \\
\hline 1 & $50: 50$ & 82 & 82 \\
\hline 2 & $60: 40$ & 75 & 87,5 \\
\hline 3 & $70: 30$ & 71,42857 & 90 \\
\hline 4 & $80: 20$ & 73,75 & 95 \\
\hline 5 & $90: 10$ & 76,66667 & 90 \\
\hline
\end{tabular}

Tabel 3 menjelaskan besarnya nilai akurasi atau ketepatan klasifikasi. Apabila melihat nilai akurasi data testing yang paling tinggi maka proposi yang terpilih yaitu 80:20 dengan nilai akurasi adalah $95 \%$ untuk data testing dan $73,75 \%$ untuk data training.

\section{Confusion Matrix}

Untuk melihat seberapa tepat suatu metode klasifikasi dapat bekerja maka sistem klasifikasi tersebut harus diukur kinerjanya. Biasanya dalam mengukur kinerja klasifikasi digunakan confusion matrix. Confusion matrix merupakan tabel yang mencatat hasil kerja klasifikasi. Berikut merupakan confusion matrix dari data testing dengan proporsi 80:20.

Tabel 4. Confusion Matrix Untuk Data Testing Dengan Proporsi 80:20.

\begin{tabular}{|l|c|c|c|c|}
\hline \multicolumn{2}{|c|}{} & \multicolumn{3}{c|}{ Kelas Hasil Prediksi } \\
\cline { 3 - 5 } \multicolumn{2}{|c|}{} & Normal & BBLR & Total \\
\hline \multirow{2}{*}{ Kelas Asli } & Normal & 17 & 1 & 18 \\
\cline { 2 - 5 } & BBLR & 0 & 2 & 2 \\
\hline \multicolumn{2}{|l}{ Total } & 17 & 3 & 20 \\
\hline
\end{tabular}

Untuk klasifikasi data latih diperoleh nilai confusion matrix yang artinya status bayi lahir yang awalnya diasumsikan normal setelah dilakukan klasifikasi dengan menggunakan PNN diperoleh hasil klasifikasi normal juga yaitu sebanyak 17, kemudian status bayi lahir yang awalnya diasumsikan BBLR dan setelah dilakukan klasifikasi dengan menggunakan PNN diperoleh hasil klasifikasi BBLR juga yaitu sebanyak 2. Status bayi lahir yang awalnya diasumsikan normal namun setelah dilakukan klasifikasi dengan menggunakan PNN diperoleh hasil klasifikasi BBLR yaitu sebanyak 1, kemudian status bayi lahir yang awalnya diasumsikan BBLR dan setelah dilakukan klasifikasi dengan menggunakan PNN diperoleh hasil klasifikasi normal yaitu sebanyak 0 . Berikut merupakan perhitungan akurasi dengan menggunakan rumus:

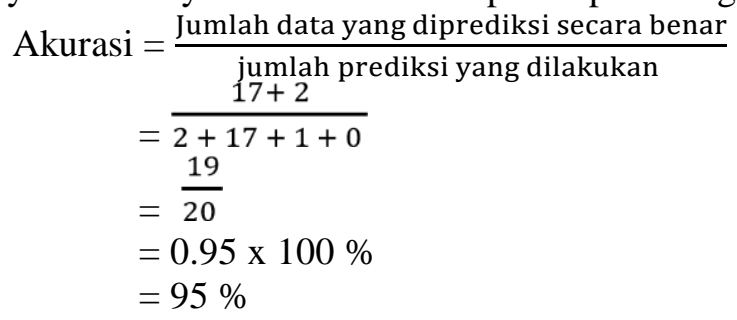

Berdasarkan perhitungan diatas, maka dapat diartikan bahwa ketepatan metode PNN dalam mengklasifikasikan berat bayi lahir berdasarkan rekam medis ibu yaitu $95 \%$.

\section{Penerapan PNN Menggunakan GUI Phyton}

Setelah diperoleh nilai akurasi tertinggi dengan proporsi data training dan data testing yaitu 80:20, maka struktur tersebut disimpan untuk digunakan dalam pembuatan GUI phyton. Adapun komponen-komponen yang terdapat pada GUI yaitu sebagai berikut :

1. Tabel untuk mengisi data rekam medis ibu seperti usia, tekanan darah sistol, tekanan 
darah diastole, berat badan, tinggi badan, hemoglobin, paritas dan lama gestasi.

2. Tombol cek status untuk mengtahui hasil klasifikasi dari input yang telah dimasukkan

3. Tombol reset untuk mengembalikan kembali ke tampilan semula, agar bisa diisi dengan data baru.

Gambar 2 merupakan salah satu contoh kasus dari pasien ibu melahirkan yang memiliki usia 25 tahun dengan tekanan darah yaitu $140 / 80 \mathrm{mmHg}$, memiliki berat badan $80 \mathrm{~kg}$ dan tinggi badan $150 \mathrm{~cm}$, serta kadar hemoglobin sebesar 11,5 g/dL, bayi yang lahir merupakan anak pertama dengan lama kehamilan yaitu 32 minggu. Hasil klasifikasi dari rekam medis tersebut menunjukan bahwa bayi akan memiliki berat badan yang normal.

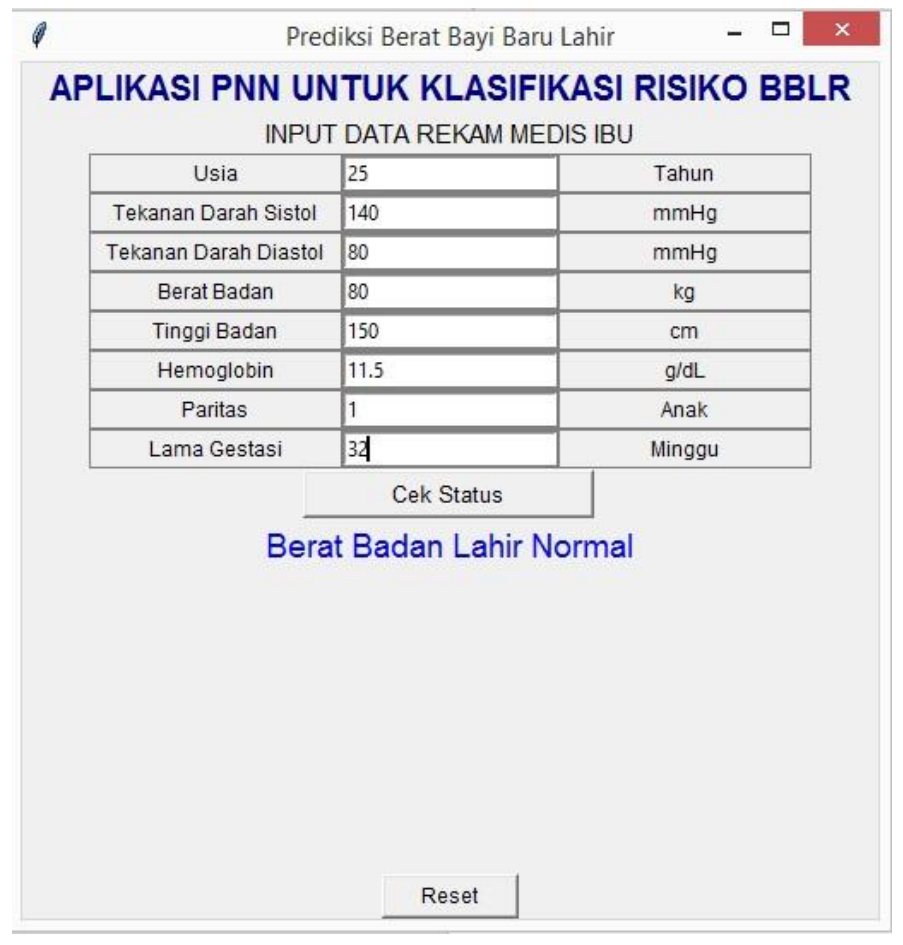

Gambar 2. Contoh Penerapan GUI

\section{Kesimpulan}

Setelah dilakukan analisis terhadap data rekam medis pasien ibu melahirkan di RSUD Kota Banjar tahun 2020, maka didapat kesimpuan bahwa pasien ibu hamil yang melahirkan bayi dengan berat badan normal ada sebanyak 64 bayi, sedangkan pasien ibu hamil yang melahirkan bayi dengan Bayi Berat Lahir Rendah (BBLR) ada sebanyak 36 bayi. Setelah dilakukan data cleaning variabel yang digunakan hanya 8 variabel prediktor dan 1 variabel respon diantaranya usia ibu, tekanan darah sistol, tekanan darah diastol, berat badan ibu, tinggi badan ibu, kadar hemoglobin, paritas, lama gestasi dan klasifikasi berat bayi lahir.

Adapun setelah dilakukan klasifikasi menggunakan PNN didapat proporsi data training dan data testing yang optimal adalah 80:20, yaitu sebanyak 80 data training serat 20 data testing. Proporsi tersebut menghasilkan nilai akurasi sebesar $95 \%$ untuk data testing dan $73,75 \%$ untuk data training. Hasil klasifikasi PNN pada 20 data testing yaitu terdapat 17 bayi yang diklasifikasikan ke dalam kelas 1 (berat bayi lahir normal) dan 3 bayi yang diklasifikasikan ke dalam kelas 2 (berat bayi lahir rendah). Penerapan PNN dapat diaplikasikan dalam kehidupan sehari-hari dengan pembuatan aplikasi GUI pada phyton. GUI ini dapat membantu memudahkan tenaga kerja medis dalam memprediksi berat bayi lahir berdasarkan rekam medis ibu

\section{Acknowledge}

Terimakasih kepada pihak-pihak yang senantiasa selalu memberi dukungan dan membantu penulis dalam menyelesaikan penelitian ini, terutama kepada Allah SWT, keluarga, dosen 
pembimbing, teman-teman yang tiada hentinya selalu memberikan masukan dan semangat kepada penulis sehingga bisa terselesaikannya penelitian ini.

\section{Daftar Pustaka}

[1] Pratama, C. D. (2020, Oktober). Faktor Penentu Kualitas Penduduk. Retrieved from Kompas.com: https://www.kompas.com/skola/read/2020/10/14/144631069/faktorpenentukualitas-penduduk

[2] kumparanSAINS. (2018, Maret). Angka Kematian Ibu dan Bayi Indonesia Tertingi Kedua di Asia Tenggara. Retrieved from kumparanSains: https://kumparan.com/kumparansains/angka-kematian-ibu-dan-bayi-indonesiatertinggikedua-di-asia-tenggara

[3] Dinas Kesehatan Provinsi Jawa Barat. (2017). Profil Kesehatan 2017. Bandung: Dinas Kesehatan Provinsi Jawa Barat.

[4] Dinas Kesehatan Kota Banjar. (2018). Laporan Kinerja Instansi Pemerintah (LKIP). Banjar: Dinas Kesehatan Kota Banjar.

[5] Yulifah, R. dan Yuswanto, T.J.A. 2009. Asuhan Kebidanan Komunitas. Jakarta: Salemba Medika.

[6] Jaya, N. (2009). Analisis Faktor Resiko Kejadian Bayi Berat Lahir Rendah di Rumah Sakit Ibu dan Anak Siti Fatimah Kota Makassar. Media Gizi Pangan Vol. VII Edisi 1, 49-54.

[7] Proverawati, A., \& Ismawati, C. (2010). BBLR: Berat Badan Lahir Rendah. Yogyakarta: Nuha Medika.

[8] Yasin, H., \& Ispriyanti, D. (2017). Klasifikasi Data Berat Bayi Lahir Menggunakan Weighted Probabilistic Neural Network (WPNN) (Studi Kasus di Rumah Sakit Islam Sultan Agung Semarang). Media Statistika, 61-70.

[9] Yi, J. H., Wang, J., \& Wang, G. G. (2016). Improved Probabilistic Neural Network With Self-Adaptive Strategies for Tranformer Fault Diagnosis Problem. Retrieved from https://doi.org/10.1177/1687814015624832

[10] Vercellis, C. 2009. Business Intelligence: Data Mining and Optimization for Decision Making. Chichester: John Wiley \& Sons Ltd.

[11] Lofti, A., \& Benyettou, A. (2014). A reduced probabilistic neural network for the classification of large databases. Turkish Journal of Electrical Engineering and Computer Sciences, 979-989. 